\title{
Gerontology
}

Published online: April 3, 2007

\section{Ian Stuart-Hamilton}

\section{The Psychology of Ageing: An Introduction, ed. 4}

Jessica Kingsley Publishers, London 2006

353 pp.; GBP 19.99

ISBN 1-84310-426-1

The book by Ian Stuart-Hamilton is an excellent introductory reading in psychology of ageing. In eight extremely well-referenced chapters it covers ageing from the normal development including a well-written overview of the biological aspects of ageing to the important questions of how to measure the intellectual changes during ageing and a thorough discussion of memory in later life, the impact of ageing on language and the interplay of personality ageing and lifestyle. A well-written chapter deals with the mental illnesses in old age. The final chapter explores the fu- ture of ageing in an increasingly technologically driven society. The extensive glossary of technical terms is very helpful. Also, the list of 47 pages of references with very recent citations (2005) underlines the high scientific level of the book. Is there a negative comment after all this praise? Just minor remarks. The importance of telomeres is probably overemphasized as being a fundamental mechanism of ageing - it is rather an indicator of the ageing process. Or that the author adopts a gloomy view of the economic future associated with longevity, despite the fact that increasing longevity is one of the greatest contributors to economic growth [Bloom and Canning: Science 2000;288:17471748]. And the rather scarce discussion of gender issues in the psychology of the very old. Despite these minor criticisms, it is a highly recommendable text for everyone interested in the psychological changes that come with ageing.

Hannes Staehelin, Basel

\section{KARGER}

\author{
(C) 2007 S. Karger AG, Basel
}

Fax +41613061234 